\title{
Metabolic control of nitrogen isotope composition of amino acids in macroalgae and gastropods: implications for aquatic food web studies
}

\author{
Yoshito Chikaraishi ${ }^{1, *}$, Yuichiro Kashiyama ${ }^{1,2}$, Nanako O. Ogawa ${ }^{1}$, \\ Hiroshi Kitazato ${ }^{1}$, Naohiko Ohkouchi ${ }^{1}$ \\ ${ }^{1}$ Institute for Research on Earth Evolution, Japan Agency for Marine-Earth Science and Technology, 2-15 Natsushima-cho, \\ Yokosuka 237-0061, Japan \\ ${ }^{2}$ Department of Earth and Planetary Sciences, University of Tokyo, Tokyo 133-0033, Japan
}

\begin{abstract}
We investigated the nitrogen isotopic compositions of individual amino acids from brown and red macroalgae and gastropods in a natural marine coastal environment, to further evaluate them as a tool for ecological studies and to understand the factor(s) controlling the isotopic compositions in terms of biosynthetic and metabolic processes. The isotopic compositions of 12 amino acids range from -2.1 to $+8.4 \%$ for brown algae, from -3.3 to $+12.9 \%$ o for red algae, and from -0.6 to $+16.6 \%$ for gastropods. The isotopic distributions between algae and gastropods and within algal classes are consistent with those in previous reports, suggesting them to be quite useful for studying food web structure. The nitrogen isotopic variation between amino acids strongly reflects their biosynthetic and metabolic processes. In particular, we suggest here that metabolic fate is an important factor in producing distinct trophic relationships in nitrogen isotopic compositions between amino acids.
\end{abstract}

KEY WORDS: Nitrogen isotopic composition · Amino acids $\cdot$ Food web $\cdot$ Trophic level $\cdot$ Biosynthesis

Resale or republication not permitted without written consent of the publisher

\section{INTRODUCTION}

Stable nitrogen isotopic composition $\left(\delta^{15} \mathrm{~N}\right)$ of whole organisms and their tissues has been widely used in a number of ecological studies (Fry 2006), particularly for elucidating the trophic level of organisms and nitrogen flow in the food web (e.g. Hobson \& Welch 1992, Keough et al. 1996, Yoshii et al. 1999, Ogawa et al. 2001, Post 2002). The method is based on observations that the $\delta^{15} \mathrm{~N}$ of organisms tends to increase with trophic level (e.g. DeNiro \& Epstein 1981, Minagawa \& Wada 1984). Although the exact mechanism of ${ }^{15} \mathrm{~N}$-enrichment is not fully understood, it has generally been considered to be related to the isotopic discrimination associated with biosynthetic and metabolic effects.

Recently, McClelland \& Montoya (2002) presented a detailed report on the trophic relationship of $\delta^{15} \mathrm{~N}$ of individual amino acids between phytoplankton (the green alga Tetraselmis suecica) and its consumer zooplankton (the rotifer Brachionus plicatilis). They sug- gested that ${ }^{15} \mathrm{~N}$-enrichment in bulk materials along the food web should strongly reflect relative abundance and the degree of ${ }^{15} \mathrm{~N}$-enrichment of amino acids in the consumer. Moreover, they suggested that ${ }^{15} \mathrm{~N}$-enrichment in some amino acids (e.g. glutamic acid) provides a greater scope for defining trophic level than small changes in bulk material, and that small changes in nitrogen isotopic compositions of other amino acids (e.g. phenylalanine) provide information on nitrogen sources at the base of the food web. Therefore, the nitrogen isotopic composition of amino acids from organisms would potentially provide a more detailed understanding of the mechanisms of ${ }^{15} \mathrm{~N}$-enrichment in bulk materials and their trophic level in an ecosystem. For example, McClelland et al. (2003) applied the method to food web structure in the tropical North Atlantic, showing that zooplankton feed on $\mathrm{N}_{2}$-fixers to a significant degree.

However, it is still uncertain whether or not the $\delta^{15} \mathrm{~N}$ relationship observed in the rotifer-green alga combi- 
nation is generally applicable to other sets of producers and consumers. Particularly, few other data are available for primary producers, even though they provide essential information on the base of the food web. Moreover, the biochemical mechanism responsible for the distinct trophic relationship of $\delta^{15} \mathrm{~N}$ value between amino acids (i.e. significant ${ }^{15} \mathrm{~N}$-enrichment in some amino acids vs. little change in others) is not well understood. Therefore, in the present study, we investigated the nitrogen isotopic compositions of individual amino acids in natural marine macroalgae and gastropods: (1) to ascertain the trophic relationship of the $\delta^{15} \mathrm{~N}$ of amino acids in a marine coastal ecosystem and (2) to discuss controlling factor(s) of the isotopic signature of each amino acid from both biosynthetic and metabolic viewpoints.

\section{MATERIALS AND METHODS}

Two brown (Heterokontophyta: Sargassum filicinum and Undaria pinnatifida) and 2 red (Rhodophyta: Binghamia californica and Gelidium japonica) macroalgae were collected from 2 to $4 \mathrm{~m}$ depth along the seacoast near Yokohama, Japan $\left(35^{\circ} 08^{\prime} \mathrm{N}\right.$, $139^{\circ} 07^{\prime} \mathrm{E}$ ) (Chikaraishi 2006). About 20 to 30 ind. for each alga were collected. This area is dominated by the brown algae and small colonies of the red algae, which are found in the vicinity of the brown algal colonies; other macroalgae are not common in this coastal area. We also collected 3 gastropods (Gastropoda: Batillus cornutus, Haliotis discus, and Omphalius pfeifferi) from the brown algal colonies. One individual from each gastropod species was collected. It has been shown that these gastropods specifically feed on brown macroalgae (e.g. Harada et al. 1984, Tutschulte \& Connell 1988, Fallu 1991). This was also confirmed in this environment by a previous investigation into the carbon and hydrogen isotopic compositions of sterols in the brown algae and gastropods (Chikaraishi 2006). After collection the macroalgae and gastropods were washed with distilled water to remove contaminants such as algal debris. The washed samples were freeze-dried, crushed to a fine powder, and stored at $-20^{\circ} \mathrm{C}$ until analysis.

The nitrogen isotopic composition of bulk sample materials was determined by an isotope ratio mass spectrometer (IRMS; ThermoFinnigan Delta plus XP) coupled to a Flash elemental analyzer (EA; ThermoFinnigan EA1112) via a Conflo III interface (e.g. Ohkouchi et al. 2005).

Amino acids were prepared for compound-specific isotope analysis by $\mathrm{HCl}$ hydrolysis, followed by $N$ pivaloyl/isopropyl (NP/iPr) addition according to the improved procedures of Metges et al. (1996). In brief, $\sim 5 \mathrm{mg}$ of each sample material was hydrolyzed with $12 \mathrm{~N} \mathrm{HCl}$ at $100^{\circ} \mathrm{C}$ for 12 to $24 \mathrm{~h}$. The hydrolysate was washed with $n$-hexane/dichloromethane $(6: 5, \mathrm{v} / \mathrm{v})$ to remove hydrophobic constituents, such as lipids, and then evaporated to dryness under a $\mathrm{N}_{2}$ stream. After derivatization with thionyl chloride/2-propanol $(1: 4, \mathrm{v} / \mathrm{v})$ at $110^{\circ} \mathrm{C}$ for $2 \mathrm{~h}$ and with pivaloyl chloride/ dichloromethane $(1: 4, \mathrm{v} / \mathrm{v})$ at $110^{\circ} \mathrm{C}$ for $2 \mathrm{~h}$, the NP/iPr derivatives of amino acids were extracted with $n$ hexane/dichloromethane $(6: 5, \mathrm{v} / \mathrm{v})$.

The nitrogen isotopic compositions of the individual amino acids were determined by gas chromatography/ combustion/isotope ratio mass spectrometry (GC/C/ IRMS) using ThermoFinnigan Delta plus XP coupled to a gas chromatograph (GC; Agilent Technologies $6890 \mathrm{~N}$ ) via combustion and reduction furnaces (e.g. Hayes et al. 1990, Brand et al. 1994). The combustion was performed in a microvolume ceramic tube with $\mathrm{CuO}, \mathrm{NiO}$, and $\mathrm{Pt}$ wires at $1000^{\circ} \mathrm{C}$, and the reduction was performed in a microvolume ceramic tube with reduced $\mathrm{Cu}$ wire at $550^{\circ} \mathrm{C}$. The GC was equipped with an Ultra-2 capillary column $(25 \mathrm{~m} \times 0.32 \mathrm{~mm}$ i.d., $0.52 \mathrm{~mm}$ film thickness; Agilent Technologies). The GC oven temperature was programmed as follows: initial temperature $40^{\circ} \mathrm{C}$ for $4 \mathrm{~min}$, ramp up at $8^{\circ} \mathrm{C} \mathrm{min}{ }^{-1}$ to $100^{\circ} \mathrm{C}$, ramp up at $6^{\circ} \mathrm{C} \mathrm{min}^{-1}$ to $220^{\circ} \mathrm{C}$, and dwell for 13 min. Carrier gas (He) flow through the GC column was $1.4 \mathrm{ml} \mathrm{min}^{-1}$. The $\mathrm{CO}_{2}$ generated in the combustion furnace was eliminated by a liquid nitrogen trap. The nitrogen isotopic composition is expressed in conventional $\delta$ notation against atmospheric $\mathrm{N}_{2}$. Standard mixtures of $8 \delta^{15} \mathrm{~N}$-known amino acids were analyzed every 4 or 5 samples to confirm the reproducibility of the isotope measurement. Analytical errors $(1 \sigma)$ of the standards were better than $0.5 \%$, with a minimum sample amount of $30 \mathrm{ng} \mathrm{N}$. The $\delta^{15} \mathrm{~N}$ of 12 amino acids (alanine, glycine, valine, leucine, isoleucine, proline, asparatic acid, threonine, serine, methionine, glutamic acid, and phenylalanine) were determined by this method (Fig. 1). The isotopic compositions of aspartic acid and threonine were reported as a mixed value, because these compounds partly coeluted on the chromatogram.

\section{RESULTS}

Fig. 1 illustrates the nitrogen isotopic results in this study. The $\delta^{15} \mathrm{~N}$ values of 12 amino acids ranged from -2.1 to $+8.4 \%$ o for the brown algae, from -3.3 to $+12.9 \%$ for the red algae, and from -0.6 to $+16.6 \%$ for the gastropods. No clear diagnostic difference was observed in the range among 4 algal as well as among 3 gastropod species. 

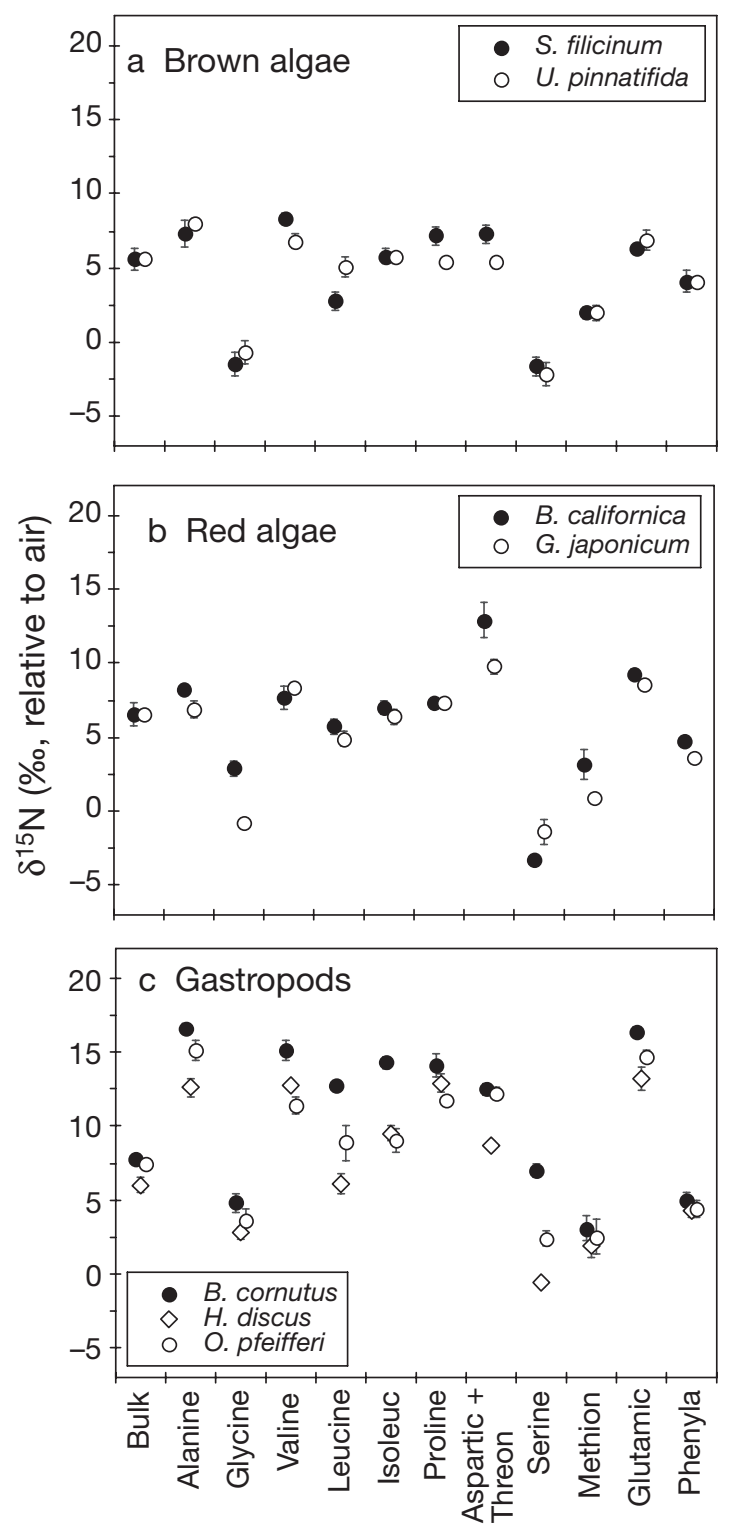

Fig. 1. Nitrogen isotopic compositions $\left(\delta^{15} \mathrm{~N}\right)$ of bulk material and individual amino acids from: (a) brown (Sargassum filicinum, Undaria pinnatifida) and (b) red (Binghamia californica, Gelidium japonicum) macroalgae, and (c) gastropods (Batillus cornutus, Haliotis discus, Omphalius pfeifferi). Error bars: standard deviation $(1 \sigma)$ of triplicate analyses. Isoleuc: Isoleucine; Aspartic + Threon: Aspartic acid + Threonine; Methion: Methionine; Glutamic: Glutamic acid; Phenyla: Phenylalanine. Aspartic acid includes asparagine; glutamic acid includes glutamine

Isotopic differences between each amino acid and bulk material $\left({ }^{15} \varepsilon_{;}{ }^{15} \varepsilon=1000\left[\left(\delta^{15} \mathrm{~N}_{\text {amino acid }}+1000\right) /\right.\right.$ $\left.\left.\left(\delta^{15} \mathrm{~N}_{\text {bulk }}+1000\right)-1\right]\right)$ for the brown and red algae are illustrated in Fig. 2, along with the differences for green algae and cyanobacteria reported by McClelland \& Montoya (2002) and McClelland et al. (2003). A large variation was observed in the ${ }^{15} \varepsilon$ values

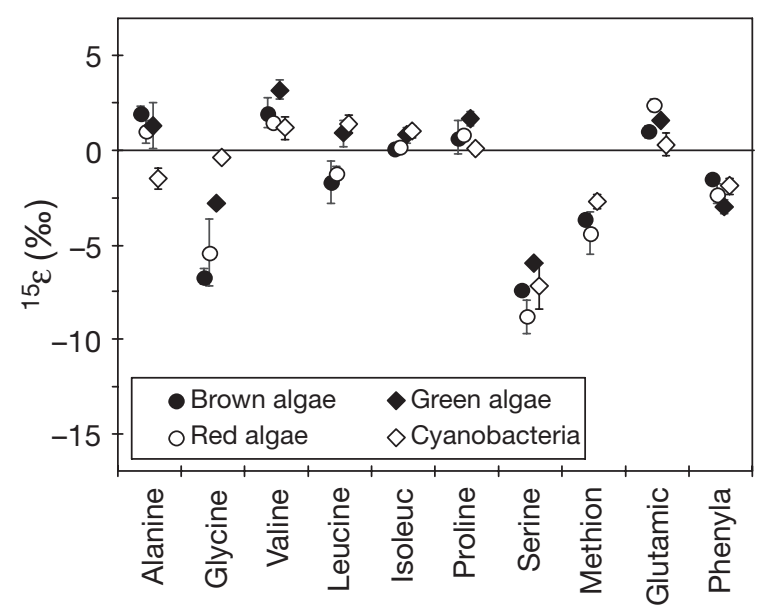

Fig. 2. Isotopic differences between amino acids and bulk material $\left({ }^{15} \varepsilon\right)$ of the brown and red algae in the present study and of the green algae and cyanobacteria in the studies by McClelland \& Montoya (2002) and McClelland et al. (2003). ${ }^{15} \varepsilon$ is defined as: ${ }^{15} \varepsilon=1000\left[\left(\delta^{15} N_{\text {amino acid }}+1000\right) /\left(\delta^{15} N_{\text {bulk }}+\right.\right.$ $1000)-1]$. Bars indicate the range from 2 species. For amino acid abbreviations see Fig. 1

between amino acids, ranging from -9.7 to $+3.7 \%$ for 3 algal classes and cyanobacteria. Generally, valine, isoleucine, proline, and glutamic acid were enriched in ${ }^{15} \mathrm{~N}$ relative to the bulk material, whereas serine, methionine, and phenylalanine were depleted in ${ }^{15} \mathrm{~N}$ relative to the bulk material. It should also be noted that the ${ }^{15} \varepsilon$ values for valine, isoleucine, proline, methionine, glutamic acid, and phenylalanine were quite similar between these marine primary producers $(1 \sigma<1.1 \%)$, whereas those of alanine, glycine, and leucine were variable between them. Particularly, glycine had the largest variation $(-7.3$ to $-0.3 \%$ ) among the primary producers studied.

Isotopic differences in each amino acid between the brown algae and gastropods $\left(\Delta_{i} \Delta=\delta^{15} \mathrm{~N}_{\text {gastropod }}-\right.$ $\delta^{15} \mathrm{~N}_{\text {brown alga) }}$ are illustrated in Fig. 3. Except for methionine and phenylalanine, the amino acids in the gastropods were significantly enriched in ${ }^{15} \mathrm{~N}$ (up to $\sim 10 \%$ ) relative to the corresponding amino acids from the food source brown algae. In contrast, methionine and phenylalanine in the gastropods demonstrated no substantial isotopic differences from those in the brown algae $(\Delta< \pm 1.2 \%$ o). Although the magnitude of ${ }^{15} \mathrm{~N}$-enrichments varied for some amino acids (e.g. glycine, leucine, and serine), the general trend of this trophic $\delta^{15} \mathrm{~N}$ relationship in the gastropod-brown alga combination was similar to the one observed in the rotifer-green alga combination (McClelland \& Montoya 2002). Particularly, the magnitude of ${ }^{15} \mathrm{~N}$-enrichment for glutamic acid was the most consistent among herbivores $(1 \sigma=1.4 \%)$. 


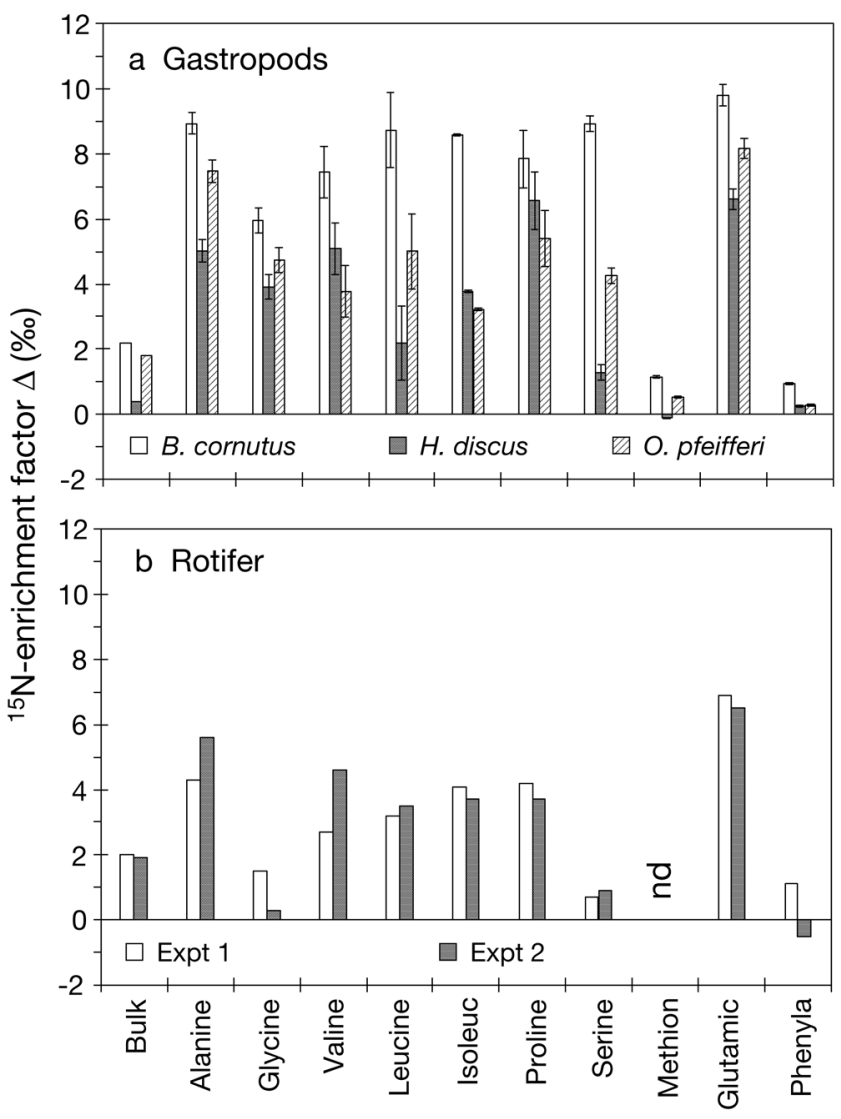

Fig. $3 \cdot{ }^{15} \mathrm{~N}$-enrichment factor $(\Delta)$ between consumer and food source of: (a) gastropods in the present study and (b) rotifers in McClelland \& Montoya (2002). $\Delta=\delta^{15} \mathrm{~N}_{\text {consumer }}-\delta^{15} \mathrm{~N}_{\text {food }}$. For gastropods, the histogram and bars represent means and ranges of $\Delta$ values from 2 species of brown algae (Sargassum filicinum and Undaria pinnatifida). nd: no data. For amino acid abbreviations see Fig. 1

\section{DISCUSSION}

Even in a single photoautotroph, the nitrogen isotopic composition of amino acids varies considerably. Such variability is partly attributable to the unique biosynthetic pathway for each amino acid (McClelland \& Montoya 2002). Indeed, amino acids are biosynthesized in photoautotrophs through various pathways from 3-phosphoglycerate, phosphoenolpyruvate, pyruvate, oxaloacetate, and a-ketoglutarate (e.g. Lengeler et al. 1999, Buchanan et al. 2000). The nitrogen is incorporated to form amino acids by enzymatic transamination of the corresponding keto acids. Therefore, the $\delta^{15} \mathrm{~N}$ values of amino acids could reflect the isotopic fractionation associated with each transamination process.

As demonstrated in Fig. 2, the ${ }^{15} \varepsilon$ values for valine, isoleucine, proline, serine, methionine, glutamic acid, and phenylalanine are quite similar among 4 macroal- gal species, as well as among green algae and cyanobacteria, even though the values differ between amino acids. This suggests that these amino acids are biosynthesized and metabolized through common pathways in aquatic photoautotrophs, even including cyanobacteria, which are phylogenically distant from the algae. In fact, the biosynthetic and metabolic pathways of these amino acids in cyanobacteria have been reported to be quite the same as those of algae (e.g. Lengeler et al. 1999, Buchanan et al. 2000). In contrast, the ${ }^{15} \mathcal{E}$ values for other amino acids, particularly for glycine, vary considerably between algal classes, suggesting them to be biosynthesized or metabolized through processes with distinct isotopic fractionations. This may reflect either a distinct kinetic isotopic effect associated with the enzymatic transaminations between algal classes or the presence of unknown biosynthetic or metabolic pathways for alanine, glycine, and leucine in these algae or cyanobacteria.

As illustrated in Fig. 3, the pattern and amplitude of the ${ }^{15} \mathrm{~N}$-enrichment of amino acids in the gastropodbrown alga combination have trends similar to those observed in the rotifer-green alga combination (McClelland \& Montoya 2002). This suggests that the results from both studies represent a general isotopic relationship in amino acids along the marine food web. Therefore, the significant ${ }^{15} \mathrm{~N}$-enrichment in some amino acids provides a scope for defining trophic level, whereas the small $\delta^{15} \mathrm{~N}$ changes in other amino acids provide information on nitrogen sources at the base of the food web, as McClelland \& Montoya (2002) suggested.

The ${ }^{15} \mathrm{~N}$-enrichment of whole organisms and tissues along the food web could be highly susceptible to the relative abundance of nitrogen-containing molecules, such as amino acids. In fact, DeNiro \& Epstein (1981) reported on a wide variation of bulk $\delta^{15} \mathrm{~N}$ difference between food sources and consumers, ranging from -0.5 to $+9.2 \%$. Moreover, the ranges of bulk ${ }^{15} \mathrm{~N}$ enrichment in 1 trophic-level shift are 0.4 to $2.2 \%$ smaller for gastropods and 1.5 to $2.0 \%$ smaller for rotifers than the value generally mentioned in food web studies (3.0\% by DeNiro \& Epstein 1981, 3.4\% by Minagawa \& Wada 1984). This is probably because the ${ }^{15} \mathrm{~N}$-enrichment in bulk materials shows an integrated ${ }^{15} \mathrm{~N}$-enrichment of various nitrogen-containing molecules in the consumer. Therefore, the trophic level of organisms could be estimated more precisely by using the ${ }^{15} \mathrm{~N}$-enrichment of specific amino acids instead of that of bulk material (Table 1). In particular, amino acids that have relatively large $\Delta$ values, with small variation among consumers (i.e. $7.6 \pm 1.4 \%$ for glutamic acid), are potentially useful as a precise tool for studying the food web structure, because they reduce error in the trophic-level calculations. 
Table 1. Calculated trophic level (TL) of the gastropod and rotifer species based on nitrogen isotopic composition of bulk material $\left(\delta^{15} \mathrm{~N}_{\text {bulk }}\right)$ and glutamic acid $\left(\delta^{15} \mathrm{~N}_{\text {glutamic acid }}\right) \cdot \mathrm{TL}_{\text {bulk }}=$ $\Delta_{\text {bulk }} / 3.4+1$ and $\Delta_{\text {bulk }}=\delta^{15} \mathrm{~N}_{\text {bulk in herbivores }}-\delta^{15} \mathrm{~N}_{\text {bulk in algaei }}{ }^{15} \mathrm{~N}$ enrichment factor $(3.4 \%$ ) is from Managawa \& Wada (1984). $\mathrm{TL}_{\text {amino acid }}=\Delta_{\text {glutamic acid }} / 7.6+1$ and $\Delta_{\text {glutamic acid }}=\delta^{15} \mathrm{~N}_{\text {glutamic }}$ acid in herbivores $-\delta^{15} \mathrm{~N}$ glutamic acid in algaei ${ }^{15} \mathrm{~N}$-enrichment factor $(7.6 \%)$ is an average of the $\Delta$ value of the gastropod-brown alga (present study) and rotifer-green alga combinations (McClelland \& Montoya 2002)

\begin{tabular}{|lcc|}
\hline Herbivores & $\mathrm{TL}_{\text {bulk }}$ & $\mathrm{TL}_{\text {glutamic acid }}$ \\
\hline Gastropods & & \\
$\quad$ Batillus cornutus & 1.7 & 1.9 \\
$\quad$ Haliotis discus & 1.1 & 2.3 \\
$\quad$ Omphalius pegeiferi & 1.5 & 2.1 \\
Rotifer (Brachionus plicatilis) & \\
B. plicatilis (first experiment) & 1.6 & 1.9 \\
B. plicatilis (second experiment) & 1.5 & 1.9 \\
after McClelland \& Montoya (2002) & & \\
& & \\
\hline
\end{tabular}

Among algal species and cyanobacteria, small variations are observed in the ${ }^{15} \varepsilon$ values of valine, isoleucine, proline, methionine, glutamic acid, and phenylalanine (Fig. 2). Moreover, no substantial changes are observed in the $\Delta$ values of methionine and phenylalanine between the algae and herbivores (Fig. 3). These results indicate that the $\delta^{15} \mathrm{~N}$ values of methionine and phenylalanine in consumers are close to those of the primary producers at the base of the marine food web. Furthermore, the original $\delta^{15} \mathrm{~N}$ values of valine, isoleucine, proline, and glutamic acid in primary producers could be reconstructed by those of methionine or phenylalanine in consumers. For example, the $\delta^{15} \mathrm{~N}$ value of glutamic acid in primary producers of the food web can be reconstructed by adding $\sim 3.4 \%$ to that of phenylalanine in consumers $\left(\delta^{15} \mathrm{~N}_{\text {glu- }}\right.$ tamic acid in primary producer $\left.=\delta^{15} \mathrm{~N}_{\text {phenylalane in consumer }}+3.4\right)$. The ${ }^{15} \mathrm{~N}$-enrichment factors of glutamic acid can be estimated by the $\delta^{15} \mathrm{~N}$ values of glutamic acid and phenylalanine in consumers $\left[\Delta_{\text {glutamic acid }}=\delta^{15} \mathrm{~N}_{\text {glutamic }}\right.$ acid in consumer $\left.-\left(\delta^{15} \mathrm{~N}_{\text {phenylalanine in consumer }}+3.4\right)\right]$. This means that the $\Delta$ value among trophic levels can be estimated by the $\delta^{15} \mathrm{~N}$ values of 2 amino acids in consumers. In other words, an isotope analysis of primary producers is not required to identify the trophic level of consumers.

Further studies are required for elucidation of the specific biochemical mechanisms responsible for the distinct trophic relationship in the nitrogen isotopic composition between amino acids. McClelland \& Montoya (2002) pointed out different biochemical behaviors between indispensable (essential) and dispensable (non-essential) amino acids. However, the indispensable and dispensable groupings are not necessarily consistent with patterns of the trophic relationship in $\delta^{15} \mathrm{~N}$ (McClelland \& Montoya 2002). For example, valine and isoleucine show significant ${ }^{15} \mathrm{~N}$-enrichment along the food web, whereas methionine and phenylalanine show small changes in $\delta^{15} \mathrm{~N}$ (Fig. 3), even though these 4 amino acids are classified as indispensable amino acids. This might be due to the fact that the indispensable and dispensable amino acids have been determined based on rats, phylogenetically very different from gastropods and rotifers, as McClelland \& Montoya (2002) pointed out.

Here, we propose an alternative, potentially important mechanism for determining the nitrogen isotopic composition of amino acids related to metabolic pathways. In heterotrophs, amino acids are acquired from food sources in excess of their need, and they are metabolized to control the nitrogen balance and protein turnover in the cell (Bender 2002). Deamination, the removal of the amine functional group, is a dominant metabolic process of many amino acids, including alanine, valine, leucine, isoleucine, and glutamic acid, in formation of the corresponding keto acids (Fig. 4). In other words, these amino acids are commonly degraded by a nitrogen-associated reaction in the first step of metabolism. Deamination is an enzymatic reaction potentially producing the nitrogen isotope discrimination between the metabolized and remaining amino acids, with the latter being theoretically enriched in ${ }^{15} \mathrm{~N}$ relative to the former. Moreover, in such cases of metabolic discrimination, the magnitude of ${ }^{15} \mathrm{~N}$-enrichment should reflect the isotope effect and relative flux of the deamination process for each amino acid, which probably causes variation in the ${ }^{15} \mathrm{~N}$ enrichment among amino acids and among herbivores. In fact, Macko et al. (1986) reported ${ }^{15} \mathrm{~N}$-enrichment of

a) Alanine, Valine, Leucine, Isoleucine, Glutamic acid

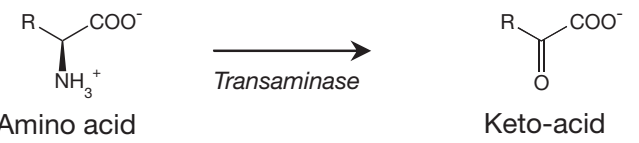

b) Methionine

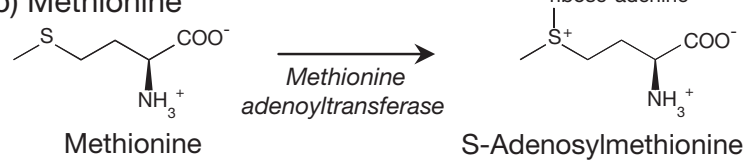

c) Phenylalanine<smiles>[NH3+]C(Cc1ccccc1)C(=O)[O-]</smiles><smiles>[NH3+][C@H](Cc1ccc(O)cc1)C(=O)O</smiles>

Fig. 4. Dominant initial steps of amino acid metabolism in animals (Bender 2002) 
$\sim 0.6 \%$ for asparatic acid and $\sim 3 \%$ for glutamic acid, after $30 \%$ deamination of the amino acids in laboratory experiments. Variation in the $\Delta$ values among amino acids and among herbivores was also observed in the present study (Fig. 3). In contrast, the dominant metabolic routes of methionine and phenylalanine lead, respectively, to the formation of S-adenosylmethiomine and tyrosine, without nitrogen-associated reactions (Fig. 4). These metabolic processes should not produce significant isotopic fractionation for nitrogen, since they neither form nor break bonds related to the nitrogen atoms in the amino acids. In fact, in our study, little change was observed in the nitrogen isotopic compositions of methionine and phenylalanine, whereas significant ${ }^{15} \mathrm{~N}$-enrichment was observed for other amino acids (Fig. 3). Thus, the $\delta^{15} \mathrm{~N}$ patterns are consistent with the metabolic fates of individual amino acids, leading us to conclude that the differences in metabolic fates among amino acids could be an important factor in producing the distinct trophic relationship in the nitrogen isotopic composition between amino acids.

Acknowledgments. We thank Mr. T. Chikaraishi for collection of samples, Dr. T. Okutani for identification of gastropod species, and Profs. H. Naraoka and S. R. Poulson for technical advice on isotopic analyses. We thank $\mathrm{Mr} \mathrm{H}$. Chikaraishi for much support and encouragement. This work was supported by research grants from the JSPS for Young Scientists (Y.C. and Y.K.) and CREST-JST (N.O.).

\section{LITERATURE CITED}

Bender DA (2002) Introduction to nutrition and metabolism. CRC Press, London

Brand WA, Tegtmeter A, Hilkert A (1994) Compound-specific isotope analysis: extending toward ${ }^{15} \mathrm{~N} /{ }^{14} \mathrm{~N}$ and ${ }^{18} \mathrm{O} /{ }^{16} \mathrm{O}$. Org Geochem 21:585-594

Buchanan BB, Gruissem W, Jones RL (2000) Biochemistry and molecular biology of plants. American Society of Plant Physiology, Rockville, MD

Chikaraishi Y (2006) Carbon and hydrogen isotopic composition of sterols in natural marine brown and red macroalgae and associated gastropods. Org Geochem 37:428-436

DeNiro MJ, Epstein S (1981) Influence of diet on the distribution of nitrogen isotopes in animals. Geochim Cosmochim Acta 45:341-351

Fallu R (1991) Abalone farming. Fishing News Books, Oxford

Fry B (2006) Stable isotope ecology. Springer, New York

Editorial responsibility: Otto Kinne (Editor-in-Chief), Oldendorf/Luhe, Germany
Harada K, Maruyama S, Nakano K (1984) Feeding attractants in chemical constituents of brown alga for young abalone. Bull Jpn Soc Sci Fish 50:1541-1544

Hayes JM, Freeman KH, Popp BN, Hoham CH (1990) Compound-specific isotopic analyses: a novel tool reconstruction of ancient biogeochemical processes. Org Geochem 16: $1115-1128$

Hobson KA, Welch HE (1992) Determination of trophic relationships within a high Arctic marine food web using $\delta^{13} \mathrm{C}$ and $\delta^{15} \mathrm{~N}$ analysis. Mar Ecol Prog Ser 84:9-18

Keough JR, Sierszen ME, Hagley CA (1996) Analysis of a Lake Superior coastal food web with stable isotope techniques. Limnol Oceanogr 41:136-146

Lengeler JW, Drew G, Schlegel HG (1999) Biology of the prokaryotes. Blackwell Science, New York

Macko SA, Fogel Estep ML, Engel MH, Hare PE (1986) Kinetic fractionation of stable isotopes during amino acid transamination. Geochim Cosmochim Acta 50:2143-2146

McClelland JW, Montoya JP (2002) Trophic relationships and the nitrogen isotopic composition of amino acids in plankton. Ecology 83:2173-2180

McClelland JW, Holl CM, Montoya JP (2003) Relating low $\delta^{15} \mathrm{~N}$ values of zooplankton to $\mathrm{N}_{2}$-fixation in the tropical North Atlantic: insights provided by stable isotope ratios of amino acids. Deep-Sea Res I 50:849-861

Metges CC, Petzke KJ, Henning U (1996) Gas chromatography/combustion/isotope ratio mass spectrometric composition of $\mathrm{N}$-acetyl and $\mathrm{N}$-pivaloyl amino acid esters to measure ${ }^{15} \mathrm{~N}$ isotopic abundances in physiological samples: a pilot study on amino acid synthesis in the upper gastrointestinal tract of minipigs. J Mass Spectrom 31:367-376

Minagawa M, Wada E (1984) Stepwise enrichment of ${ }^{15} \mathrm{~N}$ along food chains: further evidences and the relation between $\delta^{15} \mathrm{~N}$ and animal age. Geochim Cosmochim Acta 48:1135-1140

Ogawa NO, Koitabashi T, Oda H, Nakamura T, Ohkouchi N, Wada E (2001) Fluctuations of nitrogen isotope ratio of gobiid fish (Isaza) specimens and sediments in Lake Biwa, Japan, during the 20th century. Limnol Oceanogr 46: 1228-1236

Ohkouchi N, Nakajima Y, Okada H, Ogawa NO, Suga H, Oguri K, Kitazato H (2005) Biogeochemical processes in a meromictic Lake Kaiike: implications from carbon and nitrogen isotopic compositions of photosynthetic pigments. Environ Microbiol 7:1009-1016

Post DM (2002) Using stable isotopes to estimate trophic position: models, methods and assumptions. Ecology 83: 703-718

Tutshulte T, Connell J (1988) Feeding behavior and algal food of three species of abalone (Haliotis) in southern California. Mar Ecol Prog Ser 49:57-64

Yoshii K, Melnik NG, Timoshkin OA, Bondarenko NA, Anoshko N, Yoshioka T, Wada E (1999) Stable isotope analyses of the pelagic food web in Lake Baikal. Limnol Oceanogr 44:502-511

Submitted: November 8, 2006; Accepted: February 6, 2007 Proofs received from author(s): June 26, 2007 